\title{
A Current Perspective on the Assessment of Prevalence of Dengue Cases in a Territory Care Hospital Bangalore and Impact of Clinical Pharmacist Mediated Patient Counseling - A Prospective Study
}

\author{
Dr. Muchukota Sushma ${ }^{*}$, Bhoomika L2 ${ }^{2}$ Dinesh M C2, Vinutha Yadav ${ }^{2}$, Kavana.C ${ }^{2}$, Mathappan \\ Rinku² \\ ${ }^{1}$ Assistant Professor, Department of Pharmacy Practice, Gautham College of Pharmacy, Bangalore, India \\ 2Department of Pharmacognosy, Gautham College of Pharmacy, Bangalore, India
}

\begin{abstract}
A B S T R A C T
Background: Dengue is an Infectious viral disease caused by the dengue virus. Dengue fever is caused by one of four types of dengue virus. It is transmitted by "Aedes aegypti mosquito". Symptoms include Fever, Arthralgia, Myalgia and Headache etc.,. Dengue is mosquito-borne viral illness. Fluid and electrolyte losses, dengue shock syndrome, residual brain damage, Febrile convulsions, Low platelet count, Significant bleeding, Liver damage are some of the complications of dengue fever

Aim The present hospital study aims to illustrate the frequency, distribution and case fatality of dengue fever based on the variables such as age, sex and impact of clinical pharmacist mediated patient counseling.

Objectives: To evaluate the perspectives on assessment of prevalence of the dengue fever and the impact of clinical pharmacist mediated patient counseling.

To estimate the prevalence of dengue fever, educate and create awareness about dengue fever and prevent further complications. Methodology: A prospective Observational study was carried out among 150 patients for a period of 4 months from June 2019 to September 2019 in ESI hospital Indiranagar, Bangalore.

Results: Dengue fever is mostly seen among the age groups between 15-55 yrs. An excess of males were found among reported dengue cases than females $54.6 \%$ were males and $45.3 \%$ were females. High proportion of cases were reported in adult age groups (25-35 years) in both males and females, Out of 150 cases Dengue fever $89.3 \%$, Dengue hemorrhagic fever is $7.3 \%$ and Dengue shock syndrome $3.33 \%$ is fatality rate and the outcome of dengue fever is $94.66 \%$ survival rate and $5.3 \%$ death rate. Conclusion: The patients with Dengue fever $89.3 \%$ and other types are DHF, DSS $7.3 \%$ and $3.3 \%$ out of them patients with thrombocytopenia is $64.66 \%$ and the platelet transfusion done in 65 patients $(43.33 \%)$ Out of 150 dengue cases 142 patients $(94.6 \%)$ are survived and the death rate is $5.3 \%$ the early identification of complications might have increased the survival rate and decreases the mortality in Dengue fever patients.
\end{abstract}

Keywords: Dengue shock syndrome, Febrile convulsions, Thrombocytopenia Arthralgia.

A R T I C L E I N F 0: Received 20 August 2019; $\quad$ Review Completed 01 Oct. 2019; $\quad$ Accepted 04 Oct. 2019; $\quad$ Available online 15 Oct. 2019

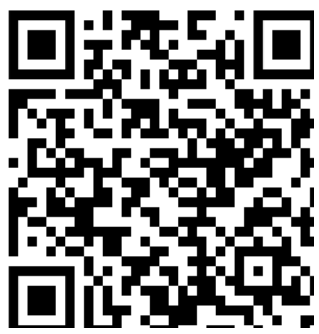

Cite this article as:

Muchukota S, Bhoomika L, Dinesh M C, Yadav N V, Kavana.C, Mathappan R, A Current Perspective on the Assessment of Prevalence of Dengue Cases in a Territory Care Hospital Bangalore and Impact of Clinical Pharmacist Mediated Patient Counseling - A Prospective Study, Asian Journal of Pharmaceutical Research and Development. 2019; 7(5):74-79, DOI: http://dx.doi.org/10.22270/ajprd.v7i5.598

*Address for Correspondence:

Dr. Sushma Muchukota, Assistant Professor, Department of Pharmacy Practice, Gautham College of Pharmacy, Bangalore.

\section{INTRODUCTION:}

$\mathrm{D}$ engue fever is a serious painful debilitating mosquito born viral disease affects of its morbidity and mortality. It is caused by any one of four distinct sero types of dengue virus (DEN2, DEN1, DEN3 and DEN4) and is transmitted within humans through female Aedes mosquitoes. Dengue disease varies from mild fever to severe conditions of dengue hemorrhagic fever and dengue shock syndrome. Globalization and spontaneous urbanization have led to increase in the rate of infection and helped dengue to expand its geographic and demographic distribution. Dengue vaccine development has been a challenging task due to the 
existence infection with DENV results in varying degrees of pathological conditions, ranging from mild asymptomatic Dengue Fever (DF) to severe Dengue Hemorrhagic Fever (DHF) and Dengue Shock Syndrome (DSS) which may turn fatal ${ }^{[1]}$.More than $70 \%$ of disease are in south east Asia and western pacific. The incidence severity of disease has increased rapidly in Latin America and the Caribbean, Brazil, Colombia and Venezuela has reported the most cases of dengue and dengue hemorrhagic fever. The WHO estimates that 50 to 100 million, infection occur yearly, including 500000 DHF cases and 22,000 deaths. Dengue percentage is more in males than females. Studies suggest that Every year 100 million cases of dengue fever and half a million cases are of dengue haemorrhagic fever (DHF) occur in the world with a case fatality in Asian countries of $0.5 \%-3.5 \%{ }^{3}$. Of those with DHF, $90 \%$ are children less than $>15$ years of age group $^{2}$. Uncontrolled population growth, unplanned and uncontrolled urbanization, insufficient wastewater management, and lack of effective mosquito control have been implicated in the increased distribution and density of the vector and also the increased spread of the virus. ${ }^{[4]}$

\section{TYPES OF DENGUE FEVER:}

- Dengue Fever

- Dengue Hemorrhagic Fever

- Dengue Shock Syndrome

Dengue fever is more frequently seen than dengue hemorrhagic fever. Dengue shock syndrome is rarely seen and death cases in dengue are less in humans. The symptoms are fever, headache, rashes, muscle pain and joint pains. The greater risk of developing of dengue fever include travelling in tropical areas, being in tropical and subtropical areas increases to exposure to virus. Thrombocytopenia is major complication seen because of dengue fever, it describes platelet count having less than $150000 \%$ microleter of blood platelet count will decreases in the day of illness.

\begin{tabular}{|l|l|l|l|}
\hline Criteria & Dengue Fever & Dengue Hemorrhagic Fever & Dengue Shock Syndrome \\
\hline \multirow{4}{*}{ Symptoms } & Fever & Abdominal pain & Liver damage \\
\cline { 2 - 4 } & Rashes & Vomiting & Myocardial depression \\
\cline { 2 - 4 } & $\begin{array}{l}\text { Joint and muscle } \\
\text { pain }\end{array}$ & $\begin{array}{l}\text { Bleeding from nose } \\
\text { (Epistaxis) }\end{array}$ & $\begin{array}{l}\text { Neurological and ophthalmological } \\
\text { manifestations }\end{array}$ \\
\cline { 2 - 3 } & Vomiting & Blood in urine & \\
\cline { 2 - 3 } & Headache & Difficulty in breathing & \\
\hline
\end{tabular}

Management of Dengue: Paracetamol is the only antipyretic prescribed for use, since other non-steroidal antiinflammatory drugs such as Aspirin or Diclofenac sodium may result in gastric irritation or provoke gastrointestinal bleeding. The recommended dose of paracetamol (60 $\mathrm{mg} / \mathrm{kg} /$ day) should not be exceeded, as otherwise liver injury that accompanies dengue viral infections may be provoked. If the temperature still remains high despite administration of paracetamol, tepid sponging is recommended. ${ }^{[5]} \mathrm{A}$ soft, balanced, and nutritious diet is recommended changing to oral rehydration fluids if a soft diet is refused. An antiemetic such as domperidone may be used to treat vomiting.

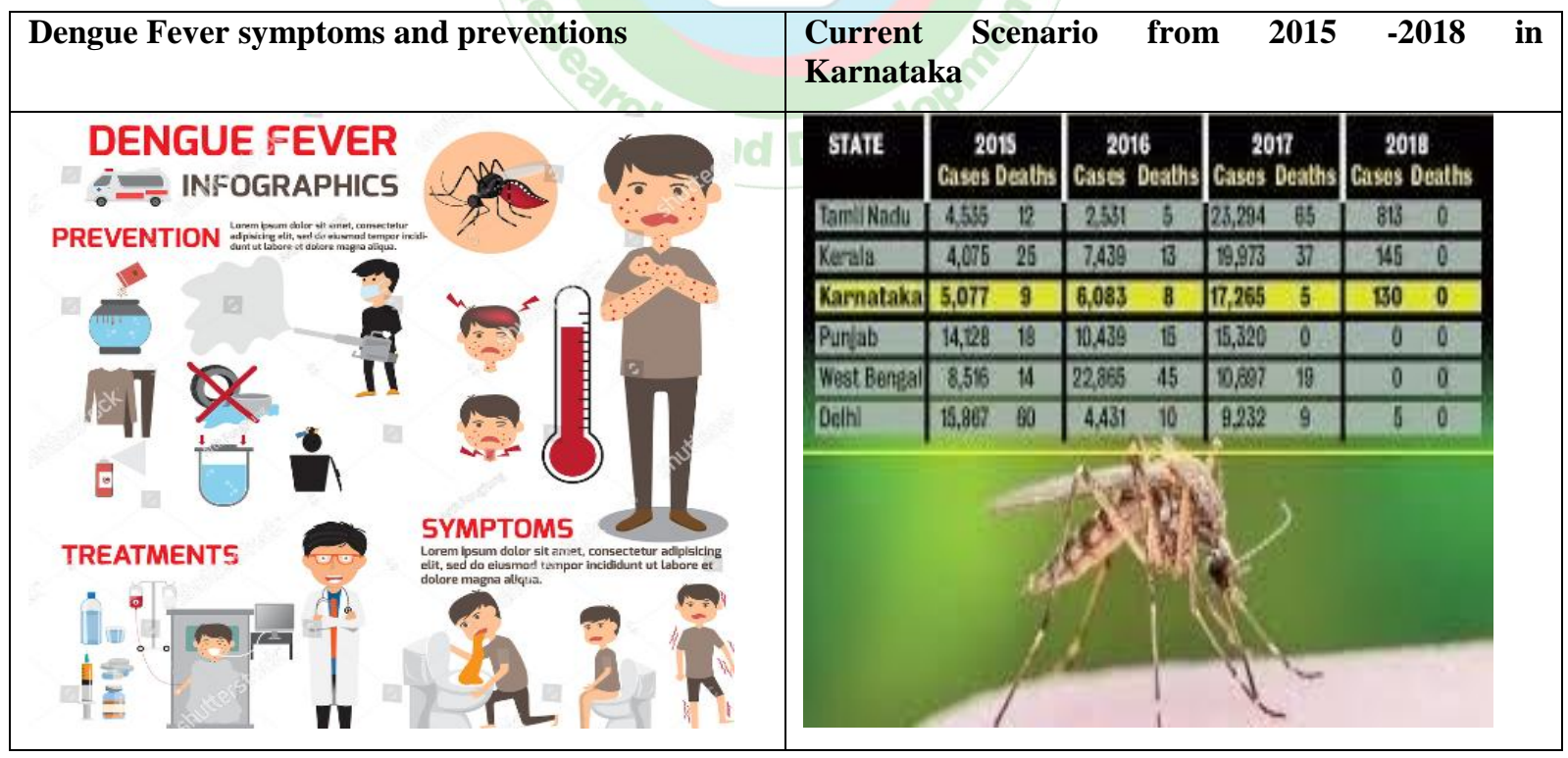

\section{AIM:}

The present hospital study aims to illustrate the frequency, distribution and fatality of Dengue cases and evaluate the perspectives on assessment of prevalence of the dengue fever based on the variables such as age, sex and impact of clinical pharmacist mediated in patient counseling.

\section{OBJECTIVE}

To assess the prevalence of dengue fever.

To educate and create awareness about dengue fever and the precautionary measures to be taken.

To provide clinical pharmacist mediated patient counseling for preventing the further complications. 


\section{METHODOLOGY:}

Study Sample: Study sample 150 In patients with age group of 5-70 years who admitted in the hospital during the study period of 4 months with dengue cases were considered into the study. [ $\mathbf{N}=\mathbf{1 5 0}$ Patients.]

Study Design: It is A Prospective, Observational and Cross Sectional study.

Study Period: The Present study was conducted for a period of Four (4) months from June to September 2019.

Study site: The Present study was conducted in Medical Ward of ESI hospital, Indiranagar, affiliated to Gautham college of pharmacy, RT nagar post, Bangalore, Karnataka, India.

\section{Study Criteria:}

\section{Inclusion criteria}

- The patients with Dengue Fever and who are willing to participate in the study.

- The patients with Age group 5-70 Years were considered into the study.

\section{Exclusion criteria}

- Patients without Dengue fever and who are not willing to participate in the study.

- Patients above 70 years age group are excluded and patients with more than $3 \mathrm{Co}$ - morbid conditions are excluded.

\section{Source of Data:}

All the patients satisfying the inclusion criteria, all the required data was collected from patients or care takers through personal interview, Patient history about disease, Patient case sheet.

\section{Method of collection of data}

All the patients satisfying the inclusion criteria were selected from Medical Department in ESI hospital, Indiranagar. After thoroughly explaining the study methodology to the subjects and then they are included in the study. Informed Consent was taken from each patient, the necessary information was collected by interviewing patients or caretakers using the following Annexures, Consent form, Data collection form and Case sheets etc., Statistical tools: Prism Graphic Pad and Microsoft excel was used to analyze the results.

\section{RESULTS:}

TABEL 1: Age Wise Distribution of Dengue

\begin{tabular}{|l|l|l|}
\hline Age (Years) & Number & Percentage \\
\hline $5-15 \mathrm{yrs}$ & 10 & $6.66 \%$ \\
\hline $15-25 \mathrm{yrs}$ & 25 & $16.66 \%$ \\
\hline $25-35 \mathrm{yrs}$ & 40 & $26.66 \%$ \\
\hline $35-45 \mathrm{yrs}$ & 35 & $23.3 \%$ \\
\hline $45-55 \mathrm{yrs}$ & 25 & $16.66 \%$ \\
\hline$>55 \mathrm{yrs}$ & 15 & $10 \%$ \\
\hline
\end{tabular}

Table 2: Gender Wise Distribution of Dengue

\begin{tabular}{|l|l|l|}
\hline Gender & Number & Percentage \\
\hline Female & 68 & $45.35 \%$ \\
\hline Male & 82 & $54.65 \%$ \\
\hline
\end{tabular}

Age wise distribution of Dengue fever

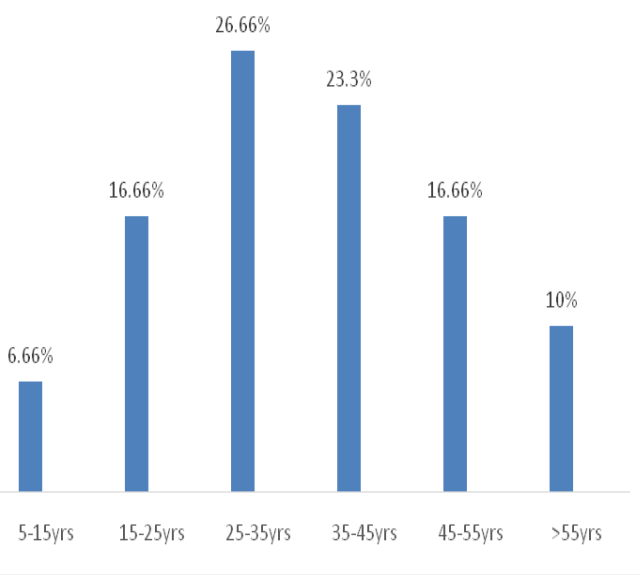

Figure 1: Age (In Years) Wise Distribution

Gender Wise Distribution

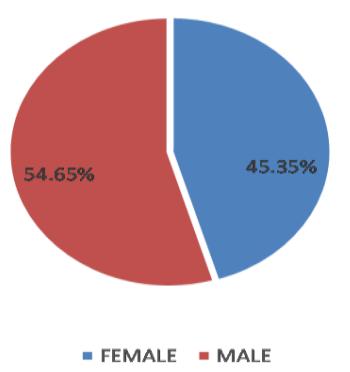

Figure 2: Gender Wise Disturubution

Table 3: Education and Employment Details

\begin{tabular}{|l|l|l|}
\hline Education & Number & Percentage \\
\hline Literates & 58 & $38.66 \%$ \\
\hline Illiterate & 92 & $61.33 \%$ \\
\hline Occupation & Number & Percentage \\
\hline Employee & 65 & $43.33 \%$ \\
\hline Unemployed & 85 & $56.66 \%$ \\
\hline
\end{tabular}

Table 4: Socio-Economic Details and Marital Status

\begin{tabular}{|l|l|l|}
\hline Socio-Economic Status & Number & Percentage \\
\hline Poor & 43 & $28.66 \%$ \\
\hline Average & 57 & $38 \%$ \\
\hline Above average & 37 & $24.66 \%$ \\
\hline Rich & 13 & $8.66 \%$ \\
\hline Marital Status & Number & Percentage \\
\hline Married & 61 & $40.66 \%$ \\
\hline Unmarried & 89 & $59.33 \%$ \\
\hline \hline
\end{tabular}


Table 5: Thrombocytopenia Details

\begin{tabular}{|l|l|l|}
\hline Thrombocytopenia & Number & Percentage \\
\hline Present & 97 & $64.66 \%$ \\
\hline Absent & 53 & $35.33 \%$ \\
\hline
\end{tabular}

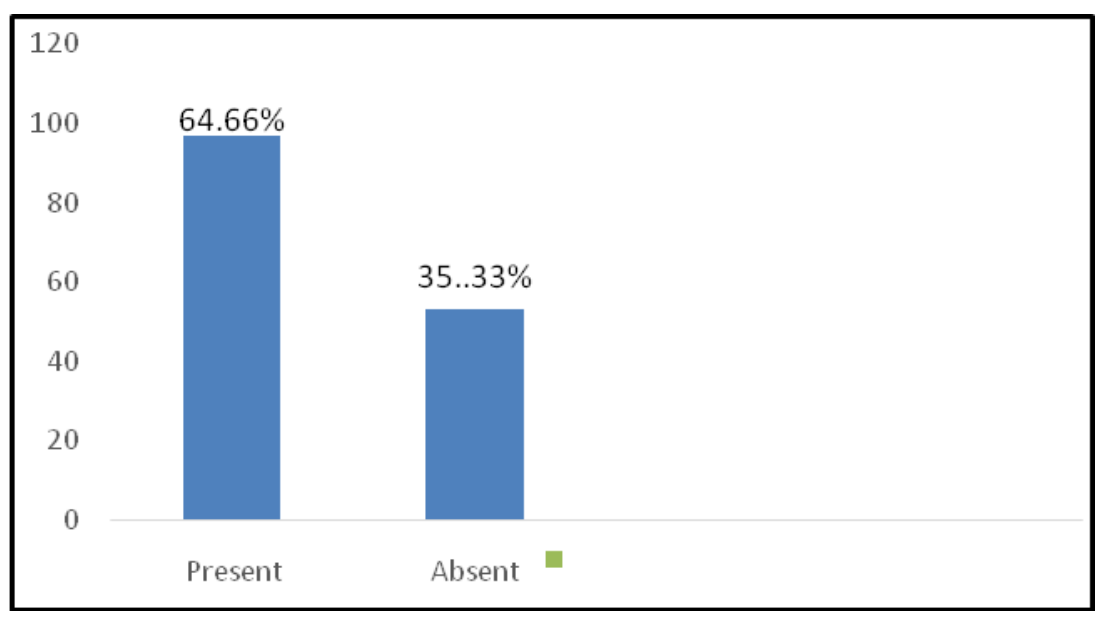

Figure 3: Thrombocytopenia Wise Distribution

Table No: 6 Platelet Count

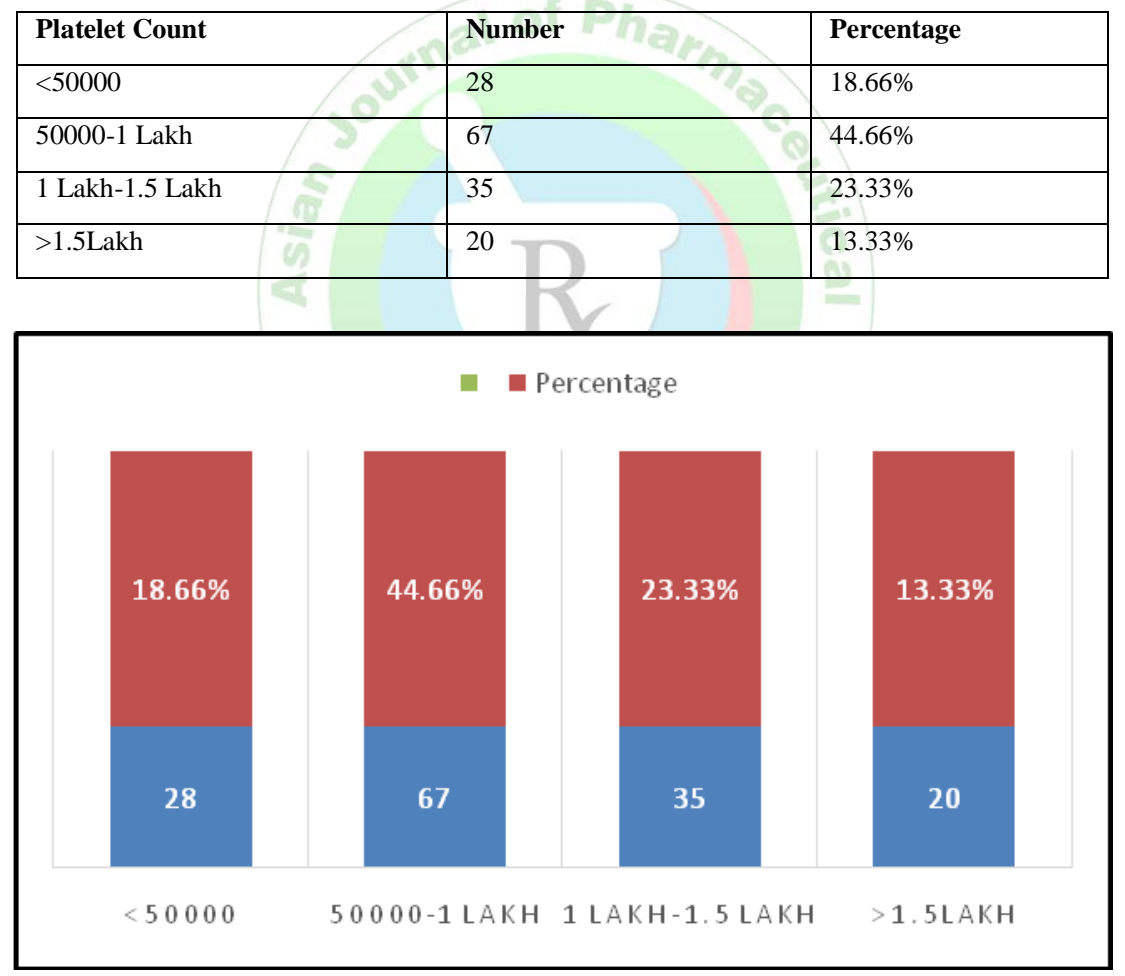

Figure 4: Platelet Count Wise Distribution

Table 7: Complications of Dengue

\begin{tabular}{|l|l|l|}
\hline Complications & Number & Percentage \\
\hline Low platelet count & 60 & $40 \%$ \\
\hline Significant bleeding & 29 & $19.33 \%$ \\
\hline Liver damage/ dysfunction & 40 & $26.66 \%$ \\
\hline Dehydration & 21 & $14 \%$ \\
\hline
\end{tabular}




\section{COMPLICATIONS}

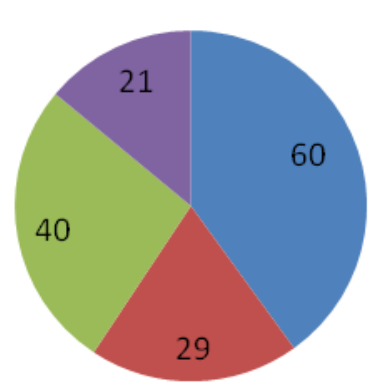

Low platelet count

Significant bleeding

Liver damage/

dysfunction

Dehydration

Figure 5: Complications Wise Distribution

Table No: 8 Types of Fever

\begin{tabular}{|l|l|l|}
\hline Types of Fever & Number & Percentage \% \\
\hline Dengue fever & 134 & $89.3 \%$ \\
\hline Dengue Haemorrhage Fever & 11 & $7.3 \%$ \\
\hline Dengue Shock Syndrome & 5 & $3.33 \%$ \\
\hline
\end{tabular}

Table 09: Types of Fever Differentiating With Symptoms

\begin{tabular}{|l|l|l|l|l|l|l|l|}
\hline \multicolumn{2}{|l|}{ Dengue Fever } & \multicolumn{2}{l|}{ Dengue Hemorrhagic Fever } & \multicolumn{2}{l|}{ Dengue Shock Syndrome } \\
\hline Symptoms & Number & $\%$ & Symptoms & Number & $\%$ & Symptoms \\
\hline Fever & 39 & $26 \%$ & Abdominal pain & 4 & $2.6 \%$ & Liver damage & 3 \\
\hline Rashes & 28 & $18.6 \%$ & Vomiting & 3 & $2 \%$ & Myocardial depression & 1 \\
\hline $\begin{array}{l}\text { Joint and } \\
\text { muscle pain }\end{array}$ & 32 & $21.3 \%$ & Bleeding from nose & 2 & $1.3 \%$ & $\begin{array}{l}\text { Neurological and } \\
\text { ophthalmological } \\
\text { manifestations }\end{array}$ & \begin{tabular}{l}
$0.6 \%$ \\
\hline Vomiting
\end{tabular} \\
\hline Headache & 30 & $4.6 \%$ & Blood in urine & 1 & $0.6 \%$ & & $0.6 \%$ \\
\hline
\end{tabular}

Table 10: Location Prevalence and Hygenic Details

\begin{tabular}{|c|c|c|}
\hline Location Prevalence & Number & Percentage \\
\hline Hebbal & 44 & $29.3 \%$ \\
\hline Indiranagar & 64 & $82.6 \%$ \\
\hline Bannerghatta & 12 & $20 \%$ \\
\hline White field & 30 & Percentage \\
\hline Hygenic Condition & Number & $12 \%$ \\
\hline Hygenic & 18 & $88 \%$ \\
\hline
\end{tabular}

Table 11: Hydration Details

\begin{tabular}{|l|l|l|}
\hline Hydration & Number & Percentage \\
\hline Iv Fluids Taken & 130 & $86.6 \%$ \\
\hline Iv Fluids Not Taken & 20 & $13.33 \%$ \\
\hline
\end{tabular}

Table 12: Platelet Transfusions

\begin{tabular}{|l|l|l|}
\hline Platelet Transfusion & Number & Percentage \\
\hline Done & 65 & $43.33 \%$ \\
\hline Not Done & 85 & $56.66 \%$ \\
\hline
\end{tabular}


Table 13: Outcome Status

\begin{tabular}{|c|c|c|}
\hline Outcome Status & Number & Percentage \\
\hline Survived & 142 & $88 \%$ \\
\hline Death & 8 & $12 \%$ \\
\hline
\end{tabular}

\section{DISCUSSION:}

According to WHO reports Dengue fever cases from many parts of the World are noticed included Africa, America, Eastern Mediterranean, Western pacific and South East Asia ${ }^{6}$. Another study conducted by Adriana et al. in Brazil ${ }^{7}$ also reveals that adult age group reveals the predominance in dengue fever. Studies show that dengue fever report more in adult age group above 20 years compared to the low age group. In the present study also dengue fever is higher in adult age groups in both males and females. A study conducted by Chia-Hsien Lin et al. in Taiwan ${ }^{[8]}$ reports that dengue fever is higher in adult age groups compared to lower age groups. In the present study, the percentage of male cases is higher than the female cases. In males, it is $54.65 \%$ and in females it is $45.3 \%$ of total dengue fever cases. A majority of the studies points out the fact that males have more outdoor work habits compared to females. They are more exposed to the mosquito bite during their day time work or while travelling to Work site and returning and returning from the work site in the late evening. A recent dengue distribution model has estimated 390 million dengue Infections annually are reported, out of which 96million cases occurred apparently ${ }^{9,10 .}$

\section{CONCLUSION:}

The patients with Dengue fever is $89.3 \%$ and other types are DHF, DSS are $7.3 \%$ and 3.3\% out of them patients with thrombocytopenia is $64.66 \%$ and the platelet transfusion done in 65 patients $(43.33 \%)$ out of them 142 patients $(94.6 \%)$ are survived and the death rate is $5.3 \%$ the early identification of complications might have increased the

\section{REFERENCES:}

1. Murphy B R , Whitehead SS, "Immune response to dengue virus and prospects for a vaccine," Annual Review of Immunology.2011; 29: 587619.

2. World Health Organization. Prevention and control of dengue and dengue haemorrhagic fever: comprehensive guidelines. WHO Regional publication, SEARO.1999; 29.

3. Halstead SB. Is there an in apparent dengue explosion Lancet 1999; 353:1100-1.

4. Guzman MG, Kouri G. Dengue: an update. Lancet Infect Dis.2002; 2: $33-42$

5. Workshop on case management of dengue hemorrhagic fever Bangkok, Thailand.2002.

6. Global strategy for dengue prevention and control. Geneva: World Health Organization; 2012; 16-7. survival rate in Dengue fever patients. As the prevention of dengue fever lacks proper vaccine, the main preventive strategy is the creating awareness in the community regarding the disease and providing the patient counselling about lifestyle and hygienic conditions, complications and disposal of wastes those in a systematic or in a proper way.

\section{RECOMMENDATIONS:}

Dengue can also be cured by drinking more fluids, papaya leaf juice and having kiwi fruit which is good for preventing the progression of dengue fever and its complications, the decreased platelet count is increased with Rehydration and also Platelet transfusion. Dengue fever also last within 2 to 3 weeks in severe condition it takes time to recover.

\section{PATIENT COUNSELLING ${ }^{11}$ :}

\begin{tabular}{|c|c|}
\hline DO'S & DONT'S \\
\hline $\begin{array}{l}\text { - Teach them about } \\
\text { warning signs, timing } \\
\text { and the critical period } \\
\text { that follows } \\
\text { defervescence. } \\
\text { - Closely monitor fluid } \\
\text { intake, output vital } \\
\text { signs and hematocrit } \\
\text { levels. } \\
\text { - Recognize and treat } \\
\text { early shock. } \\
\text { - Administer colloids } \\
\text { such as albumin for } \\
\text { refractory shock. }\end{array}$ & 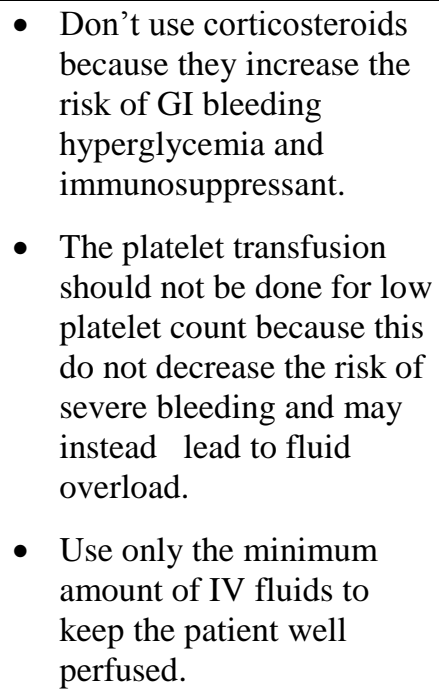 \\
\hline
\end{tabular}

7. Guilarde AO, Turchi MD, Siqueira JB Jr, Feres VC, Rocha B, Levi JE, et al. Dengue and Dengue Haemorrhagic Fever among adults. Clinical outcomes related to Viremia, Serotypes and Antibody response. J Infect Dis $2008 ; 197: 817-24$

8. Lin CH, Schiøler KL, Jepsen MR, Ho CK, Li SH, Konradsen F. Dengue outbreaks in high income area, Kaohsiung city, Taiwan, 2003-2009. Emerg Infect Dis 2012; 18:1063-11.

9. S. Bhatt, P.W. Gething, O. J.Brady et al., "The global distribution and burden of dengue," Nature.2013; 496: 504-507.

10. O. J. Brady, P. W. Gething, S. Bhatt et al., "Refining the global spatial limits of dengue virus transmission by evidence-based consensus," PLoS Neglected Tropical Diseases.2012; 6(8):1760.

11. Centers for Disease control and prevention, National center for emerging and zoonotic infectious diseases. 